\title{
TRANSIENT ISCHEMIC ATTACKS IN A CHILD WITH POST-VARICELLA ARTERIOPATHY AND MTHFR HOMOZIGOTIC MUTATION C677T
}

\author{
Pedro Beleza', João Fernandes², Ana Afonso ${ }^{3}$, Helena Silva ${ }^{3}$, Maria J. Jordão
}

Acute arteriopathies represent $79 \%$ of stroke in children'. Chickenpox is the primary etiologic agent involved in $60 \%$ of cases and usually carries a good prognosis ${ }^{2}$. We report on a patient with multiple transients ischemic attacks (TIA) who presented a post-varicella artheriopathy (PVA) associated with MTHFR homozigotic mutation C677T. Moreover the diagnosis criteria and therapy of PVA is discussed.

\section{CASE}

A three year-old boy was admitted to the emergency room (ER) with sudden onset of transient motor deficit of both left limbs. The neurological and general examination was normal. His past medical history was remarkable for primary varicella infection occurring five months before. In the ER he underwent blood tests, brain CT and EEG which displayed normal results. While performing $\mathrm{EEG}$, he presented another deficit episode lasting for five minutes and similar to the one previously described. In the light of multiple TIA's, anticoagulation with heparin was initiated. However, he had three more TIA's in the same territory, and at the fifth day after admission had sudden onset of a left pyramidal syndrome with discrete hemiparesis.

The heart evaluation including electrocardiogram and echocardiogram was normal. Noteworthy, concearning the analyti-

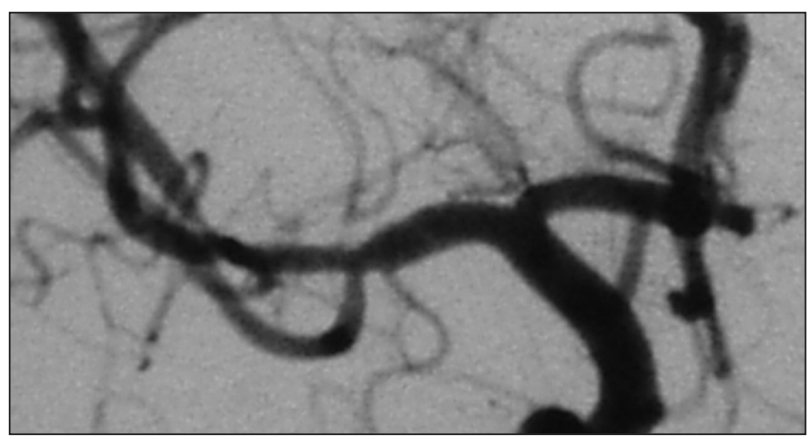

Fig 2. Digital subtraction angiography, right internal carotid injection, frontal projection. Stenosis of distal M1 and proximal M2 segments is confirmed.

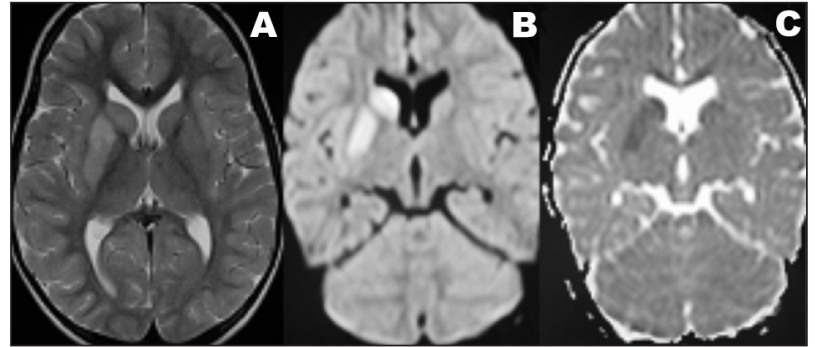

Fig 1. MRI at day 2 after admission reveals recent striatum infarction with T2-hyperintensity (A) and restricted diffusion (B, C).

cal work-up, we underscore the serologic evidence of a non-recent VVZ infection (IgG+, IgM-) and the presence of a MTHFR homozigotic mutation C677T with normal homocystein and folic acid. All the remaining study was normal or negative and included hemogram, biochemistry, immunologic study, metabolic, protrombotic and CSF (cytochemistry, serologic, microbiologic and virus PCR including VVZ). The MRI with Angio-MRI performed at the second day after admission showed a recent stroke in the territory of right lenticulostriate arteries and a decreased flow on the M1-M2 transition of right MCA (Fig 1). A brain conventional angiography was performed to better study all the brain vascular system including the distal vessels. The intracranial es-

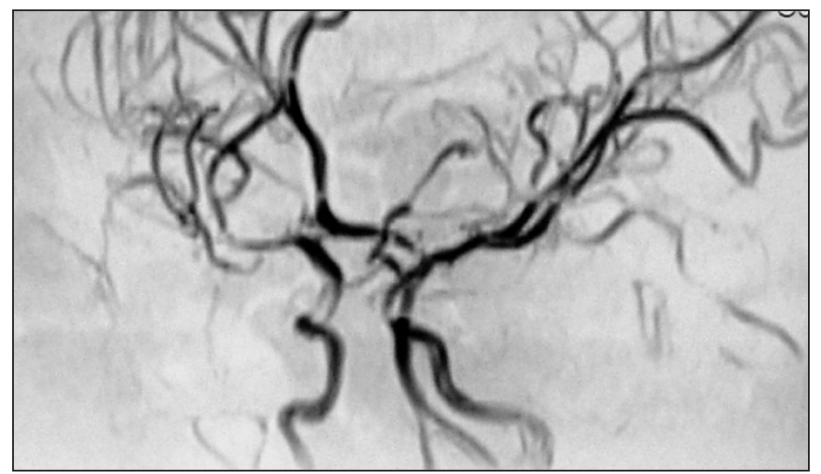

Fig 3. MR-angiography, 3D Time-of-flight at 3 month follow up, demonstrates reversion of stenosis of $\mathrm{M} 1$ segment.

\section{ACIDENTES ISQUÊMICOS TRANSITÓRIOS EM CRIANÇA COM ARTERIOPATIA PÓS-VARICELA E MUTAÇÃO MTHFR C677T HOMOZIGÓTICA}

São Marcos Hospital, Braga, Portugal: 'MD, Department of Neurology; ${ }^{2} \mathrm{MD}$, Department of Pediatry; ${ }^{3} \mathrm{MD}$, Department of Neuroradiology.

Received 23 October 2007, received in final form 2 January 2008. Accepted 20 February 2008.

Dr. Pedro Beleza - Serviço de Neurologia / Hospital São Marcos - Largo Carlos Amarante, Apartado 2242 - 4701-965 Braga - Portugal. E-mail: beleza.76@gmail.com 
tenosis of the right MCA was confirmed and other vascular abnormalities were excluded (Fig 2). Despite showing therapeutic APTT levels he had another similar TIA at the $9^{\text {th }}$ day. Thus, acetilsalicilic acid (ASA) $3 \mathrm{mg} / \mathrm{Kg} /$ day was associated. As he presented the MTHFR homozigotic mutation C677T it was provided folic acid $2.5 \mathrm{mg} /$ day. The diagnostic suspicion was a post-varicella arteriopathy, so he was treated with acyclovir $30 \mathrm{mg} / \mathrm{kg} /$ day for eight days. Since, that time he had no more stroke recurrences. The follow-up MRI with AngioMRI performed at the $21^{\text {th }}$ day yielded identical results to the previous one. He was discharged home treated with warfarin, ASA and folic acid. Three months later, a MRI with AngioMRI (Fig 3) revealed a complete reversion of stenosis and thus hypocoagulation was stopped.

\section{DISCUSSION}

The patient reported presents clinical and imagiological features compatible with PVA according to Lanthier et al. $^{3}$ : first ever stroke ocurring within one year after primary varicella; stroke manifestations and cerebral infarct location consistent with unilateral vascular disease affecting the distal internal carotid arteery (ICA) or proximal segments of anterior caratid artery (ACA) or medium carotid artery (MCA); cerebral vessel imaging showing vascular stenoses of these arterial segments. Moreover, corroborating the diagnosis of PVA, the arteriopathy took a monophasic course with subsequent stenosis regression, which was proved to be the most common clinical evolution ${ }^{3}$. The mode of onset of stroke in our patient was with multiple TIAs, which was demonstrated to predict an underlying artheriopathy ${ }^{4}$. This fact guided us to perform vascular imaging as soon as possible, which led to the diagnosis of PVA in the second day after admission. The follow-up of the arteriopathy was performed with AngioMRI since transcranial Doppler proved to have less sensibility in case of minimal arterial stenoses or in case of lesions located in arterial segments other than $\mathrm{MI}^{5}$.

Primary varicella is known to be an important risk factor for cerebral infarction in childhood inasmuch as in idiopathic arterial ischemic stroke (AIS), the incidence of varicella-related strokes increases 6 fold (to 50\%) compared to population rates ${ }^{6}$. Although the absolute risk of varicella-associated AIS is estimated at only 1 in 150000 children ${ }^{7,8}$. Variations in immune susceptibility or in the strain of the VZV may account for different susceptibility to varicella-related AIS. However, HLA-B51, a promising immunogenetic marker for predisposition to vascular oclusion in response to an immunological study failed to show association with PVA'. The reasons for that such a small subgroup of children with varicella experience AIS are not yet known. Evidence of varicella-zoster virus within the vessel wall of diseased arteries is found at autopsy in children with PVA ${ }^{10}$ and in adults with cerebral arteritis associated with herpes zoster ophtalmicus ${ }^{11}$, supporting that childhood PVA results from viral migration from the trigeminal ganglion and nerve to the major arteries. Regarding therapy, a review on varicella-associated stroke showed no obvious benefit of antiviral drugs or corticosteroid therapy because most children recovered nearly completely regardless therapy, although the authors advocated antiviral therapy because of suspected recent viral replication in such cases ${ }^{12}$. Other studies suggest that anticoagulant therapy in the initial phases of varicella-associated AIS may be helpful in preventing local extension of the thrombus and embolization ${ }^{13}$.

Additionally, our patient presented MTHFR C677T homozygotic mutation with normal homocystein levels, which was demonstrated to determine susceptibility to ischemic stroke inasmuch as in a large pediatric series ( $n=148$ ) the OR associated with the TT genotype was $2.6^{14}$. Despite this associated finding we still considered the diagnosis of PVA because it presents typical clinical and imagiological features which could not be explained only by the prothrombotic abnormality. The combination with chickenpox might have triggered the occurrence of stroke in our patient. Multiple risk factors were seen in $24 \%$ of stroke in children ${ }^{15}$. Their identification may represent a change in therapeutic management and also predicts a poor outcome, namely stroke recurrence ${ }^{15}$. Thus is crucial to perform a complete investigation which should include vascular imaging, cardiac evaluation and prothrombotic testing ${ }^{16}$. Actually, although stroke in children is commonly associated with the presence of both genetic and acquired risk factors ${ }^{17}$ this is one of the rare patients reported in the literature with stroke and PVA combined with a prothrombotic disorder ${ }^{18}$. The rarity of this finding, can be due to the underinvestigation of additional risk factors in children with varicella and stroke which would justify at least partially why only some children with varicella develop AIS, an issue that diserves documentation in further studies. In addition, another possible explanation is the clinical use of strict diagnostic criteria as defined for typical PVA by Lanthier et al. ${ }^{3}$ in a research context, thereby excluding cases with atypical PVA, such as those with multiple possible stroke aetiologies. Unfortunatelly, further studies did not arise the issue of what diagnostic criteria should be applied in clinical practice. We suggest that in clinical grounds PVA might be diagnosed according to the originally criteria proposed by Lanthier et al. $^{3}$, although we would not consider it as a diagnosis of exclusion. Actually the co-existence of a metabolic or a prothrombotic disorder with an arteriopathy fulfilling all the criteria previously cited of PVA $^{3}$ should not prevent to perform a diagnose of PVA.

In summary, our case study underscores the importance of performing a complete investigation in children 
with stroke and PVA, which should always include prothrombotic testing. Actually the identification of an associated prothrombotic abnormality can represent a change in the therapeutic management and also signify stroke recurrence. We also suggest that the clinical diagnosis of PVA should be based in the criteria proposed by Lanthier et al. ${ }^{3}$, although should not be considered a diagnosis of exclusion.

\section{REFERENCES}

1. Ganesan V, Prengler M, McShane MA, Wade AM, Kirkham FJ. Investigation of risk factors in children with arterial ischemic stroke. Ann Neurol 2003;53:167-173.

2. Guillot M, El Hachem C, Amiour M, et al. [Varicella, acute postinfectious arteriopathy and cerebral arterial thrombosis in childhood: a unique clinical and etiologic framework to be fully acknowledged]. Arch Pediatr 2005;12(Suppl 1):S58-S60.

3. Lanthier S, Armstrong D, Domi T, deVeber G. Post-varicella arteriopathy of childhood: natural history of vascular stenosis. Neurology 2005; 64:660-663.

4. Braun KP, Rafay MF, Uiterwaal CS, Pontigon AM, DeVeber G. Mode of onset predicts etiological diagnosis of arterial ischemic stroke in children. Stroke 2007:38:298-302.

5. Rougeot C, Boissier C, Chabrier S. Post-varicella arteriopathy: benefits of using serial transcranial Doppler examinations. Eur J Paediatr Neurol 2006;10:152-153.

6. Sebire G, Meyer L, Chabrier S. Varicella as a risk factor for cerebral infarction in childhood: a case-control study. Ann Neurol 1999;45:679-680.
7. deVeber G. The Canadian Pediatric Ischemic Stroke Study Group. Canadian paediatric ischemic stroke registry: analysis of children with arterial ischemic stroke. Ann Neurol 2000;27(H-08).

8. Chickenpox in Canada, 1924-87. Cmaj 1988;138:133-134.

9. Kluger G, Hubmann M, Vogler L, Berz K. Lack of association between childhood stroke after varicella and human leukocyte antigen (HLA)B51. Eur J Paediatr Neurol 2001;5:259-260.

10. Berger TM, Caduff JH, Gebbers JO. Fatal varicella-zoster virus antigenpositive giant cell arteritis of the central nervous system. Pediatr Infect Dis J 2000;19:653-656.

11. Gilden DH, Kleinschmidt-DeMasters BK, LaGuardia JJ, Mahalingam R . Cohrs RJ. Neurologic complications of the reactivation of varicellazoster virus. N Engl J Med 2000;342:635-645.

12. Moriuchi H, Rodriguez W. Role of varicella-zoster virus in stroke syndromes. Pediatr Infect Dis J 2000;19:648-653.

13. Askalan R, Laughlin S, Mayank S, et al. Chickenpox and stroke in childhood: a study of frequency and causation. Stroke 2001;32:1257-1262.

14. Nowak-Gottl U, Strater R, Heinecke A et al. Lipoprotein (a) and genetic polymorphisms of clotting factor $\mathrm{V}$, prothrombin and methylenetetrahydrofolate reductase are risk factors of spontaneous ischemic stroke in childhood. Blood 1999;94:3678-3682.

15. Lanthier S, Carmant L, David M, Larbrisseau A, de Veber G. Stroke in children: the coexistence of multiple risk factors predicts poor outcome. Neurology 2000;54;371-378.

16. Pediatric Stroke Working Group. Stroke in childhood: November 2004. Available at: http:/ / www.rcplondon.ac.uk/pubs/books/childstroke.

17. Barreirinho S, Ferro A, Santos M, et al. Inherited and acquired risk factors and their combined effects in pediatric stroke. Pediatr Neurol 2003; 28:134-138.

18. Miravet E, Danchaivijitr N, Basu H, Saunders DE, Ganesan V. Clinical and radiological features of childhood cerebral infarction following varicella zoster virus infection. Dev Med Child Neurol 2007;49:417-422. 